\title{
Studies of the Chemical and Structural Heterogeneity of the Technological Model of the Fusion Boundary of Pearlitic Steel and the Material of the Anticorrosive Cladding of VVER
}

\author{
V. N. Skorobogatykh, N. P. Anosov, P. A. Kozlov, L. Yu. Gordyuk, \\ A. S. Gudenko, A. A. Korneev, E. M. Simich-Lafitskaya, and E. V. Pogorelov \\ JSC NPO CNIITMASH, Moscow, Russia
}

\section{Abstract}

The properties of ingots of variable chemical composition are investigated. The ingots simulated the fusion boundary of heterogeneous steels of pearlitic and austenitic

Corresponding Author: Egor V. Pogorelov EVPogorelov@cniitmash.com

Received: 21 December 2017

Accepted: 15 April 2018

Published: 6 May 2018

Publishing services provided by Knowledge

(c) V. N. Skorobogatykh et al. This article is distributed under the terms of the Creative Commons Attribution License, which permits unrestricted use and redistribution provided that the original author and source are credited.

Selection and Peer-review under the responsibility of the MIE-2017 Conference Committee.

\section{G OPEN ACCESS} grade, used as structural for VVER-type reactors. The distribution of chemical elements and hardness, microstructure was studied. The phase composition of the ingots was studied using thermodynamic modeling. It was found that the distribution of alloying elements, hardness and phase composition is nonlinear. In ingots, a zone of a sudden change in hardness was detected, from $350 \mathrm{HB}$ to $150 \mathrm{HB}$, ingot 1 , and from $250 \mathrm{HB}$ to $160 \mathrm{HB}$, ingot 2. A study of the phase composition and microstructure showed that at a ratio of the austenite phase to the ferritic $(71-76) \%$ to $(29-24) \%$, a sharp change in hardness is observed.

Keywords: heterogeneous welded joints and cladding, fusion boundary, technological modeling, thermodynamic modeling.

\section{Introduction}

An important condition is an understanding of the processes of phase and structural transformations occurring in materials operating under pressure under conditions of prolonged thermal and / or radiation exposure, when designing and operating power equipment. Of particular interest are the processes occurring in the metal of the heterogeneous welded joints and cladding, near the fusion line and in the heat-affected zone, since they largely limit the resource of power equipment [1-4].

When two components differing in the phase composition are melted, the appearance of interlayers of a metal of variable composition is characterized [5-7]. The width of the fusion boundary does not exceed $0.2-0.5 \mathrm{~mm}$, when welding and surfacing the 
VVER body materials $[7,8]$. The small size of the zone makes it very difficult to study the mechanical properties of metal by traditional methods [7].

The combination of modern research methods, in particular computer modeling and the creation of full-scale models of welded joints, is an effective way of investigating processes taking place in such small volumes. The development of methods for obtaining ingots of variable chemical composition and structure makes it possible to work with more convenient specimen sizes for samples and significantly reduces the cost of research (ingots up to $300 \mathrm{~mm}$ in length).

\section{MATERIALS AND METHODS}

A modern way of studying the processes occurring in microvolumes is the use of the CALPHAD method of computational thermodynamics and kinetics, which have found wide application in the study of similar problems [9]. To date, there are a number of software packages that implement the CALPHAD method. In work, for numerical methods of thermodynamics modeling, Thermo-Calc software will be applied.

Two ingots (ingot 1 and ingot 2) of variable chemical composition were made to investigate welded joints and cladding that simulate the increased zone of chemical heterogeneity of fusion of pearlite steel and austenitic steel. The ingots are obtained by electroslag remelting (ESR) of the melted electrode. The electrode was obtained by fusing two wedges of steel type ${ }_{15} \mathrm{Cr} 2 \mathrm{NiMoVA}$ and steel type 08Cr25Ni13 (Figure 1). Table 1 presents the chemical compositions of the alloys studied. To ingot 2, a double ESR remelting was used to improve the quality of the ingot.

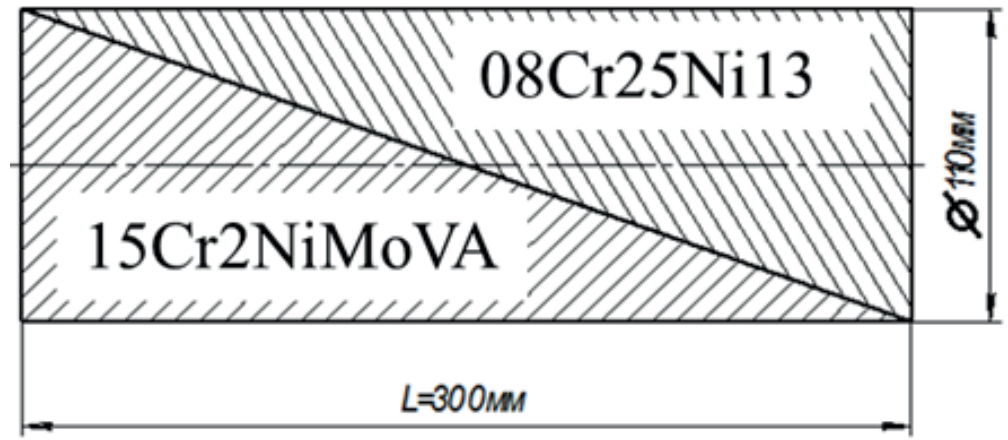

Figure 1: The scheme for obtaining a remelted electrode for melting an ingot of variable chemical composition by the ESR method.

A study was made of the various properties of ingots of variable chemical composition in the state after heat treatment. It was studied: a change in hardness, the distribution of alloying elements, a change in the structural and phase compositions 
TABLE 1: The required chemical composition of alloys used to create an alloy of variable chemical composition.

\begin{tabular}{|c|c|c|c|c|c|c|}
\hline \multirow[t]{2}{*}{ Grade } & \multicolumn{6}{|c|}{ Content of alloying elements, mass $\%$} \\
\hline & C & $\mathrm{Si}$ & & & $\mathrm{Cr}$ & $\mathrm{Ni}$ \\
\hline 15Cr2NiMoVA & $0,13-0,18$ & $0,17-0,37$ & 0,30 &, 60 & $1,8-2,3$ & $1,0-1,5$ \\
\hline o8Cr25Ni13 & $\leq 0,09$ & $0,5-1,4$ & 0,8 & & $22-26$ & $11-14$ \\
\hline Grade & Mo & V & $\mathrm{Ti}$ & $\mathrm{Cu}$ & S & $P$ \\
\hline${ }_{15} \mathrm{Cr} 2 \mathrm{NiMoVA}$ & $\begin{array}{c}0,50- \\
0,70\end{array}$ & $\begin{array}{c}0,10- \\
0,12\end{array}$ & $<0,01$ & $<0,08$ & $<0,012$ & $<0,010$ \\
\hline $08 \mathrm{Cr}_{25} \mathrm{Ni13}$ & $\leq 0,25$ & & $<0,01$ & & 0,015 & 0,022 \\
\hline
\end{tabular}

along the axis of the ingots. The thermal treatment of the ingots under study is a twostage tempering: the first tempering at a temperature $T=(620 \pm 10)^{\circ} \mathrm{C}$, an exposure time of $10 \mathrm{~h}$, a second tempering at a temperature $T=(650 \pm 10) \mathrm{C}$, holding for 15 hours.

The hardness test was carried out using the Brinell method at a facility TB 5004-003 at a load of $750 \mathrm{~kg}$ and an indentor diameter of $5 \mathrm{~mm}$. The content of the chemical elements was determined using the PMI-MASTER optical emission spectroscopy, the KFK-2MP photoelectric colorimeter and the LECO CS-244 analyzer of carbon and sulfur. A more detailed measurement of the content of chromium, nickel and copper in ingot 1 was carried out on a scanning electron microscope JEOL 6060 with an energy dispersive attachment JED-2300 by micro-X-ray spectral analysis. A microstructural study of ingot 1 was performed using the Axiovert 40 MAT microscope (Carl Zeiss, Germany) equipped with a digital image analyzer ProgRes $C_{3}$. An investigation of the change in the phase composition was carried out by thermodynamic modeling using the ThermoCalc program (with the TCFE 6.o database) for thermodynamic modeling.

\section{RESULTS}

\subsection{Distribution of alloying elements}

Figure 2 shows the distribution of alloying elements in an ingot of electroslag smelting (ingot 1) and with repeated electroslag remelting (ingot 2). The change in the content of alloying elements: chromium, nickel, carbon, silicon, manganese, molybdenum, vanadium, titanium and copper is nonlinear and monotonic for both ingots. There is a large gradient in the content of elements at a distance from $25-50$ to $180-250 \mathrm{~mm}$ from 
the beginning of the measurements (the edge corresponding to the composition of ${ }_{15} \mathrm{C}$ r2NiMoVA). A noticeable decrease in the gradient of the concentration of alloying elements is observed in an ingot with a double ESR remelting.

\subsection{Hardness}

Figure 3 shows the study of changes in the hardness of ingots along the axis. As the distance from the measurement starts to increase, the hardness values increase from 250 to $300 \mathrm{HB}$ (ingot 1) and 180 to $200 \mathrm{HB}$ (ingot 2), to 300 to $350 \mathrm{HB}$ (ingot 1) and 220 to $250 \mathrm{HB}$ (ingot 2). Further, a fracture is observed on the graph and the hardness values are reduced to $125-160 \mathrm{HB}$ (ingot 1 and 2). After the value of the hardness increase to $200-250 \mathrm{HB}$ (ingot 1) and $150-170 \mathrm{HB}$ (ingot 2). An investigation of the macrostructure of ingot 1 confirmed the possible presence of a sharp change in hardness (Figure 4).

The hardness of the ingots in the first section increases due to hardening of the solid solution, because of to an increase in the content of alloying elements and an increase in the content of the carbide phase $M_{23} C_{6}$.

\section{3. microstructure}

Scheffler diagram is a convenient tool for determining the structure of steels [12]. The structure of the steel is determined by the number of ferrite-stabilizing and austeniticstabilizing elements expressed by the chromium-nickel equivalent. The equivalents of chromium and nickel are calculated as linear combinations of mass percentages of the main components with constant coefficients [13]:

$$
\begin{gathered}
C r_{e q}=C r+2 * S i+1,5 * M o+5 * V+5,5 * A l+1,75 * N b+1,5 * T i+0,75 * W \\
N i_{e q}=N i+30 * C+0,5 * M n+0,3 * C u+C o+25 * N
\end{gathered}
$$

Data on the distribution of alloying elements in ingots 1 and 2 (see above) were used as initial data. The evolution of the structure of ingots of variable composition along the axis was obtained (Figure 5).

The diagram of Sheffler shows that in ingots 1 and 2, as the distance from the edge of the ingot increases, the structure of the ingot changes from martensitic, to duplex (austenite + martensite), then to a two-phase austenitic-ferritic (probably with the formation of a sigma phase). A comparison of the hardness and data obtained with the Schaeffler diagram showed that a sharp decrease in hardness is observed in the 


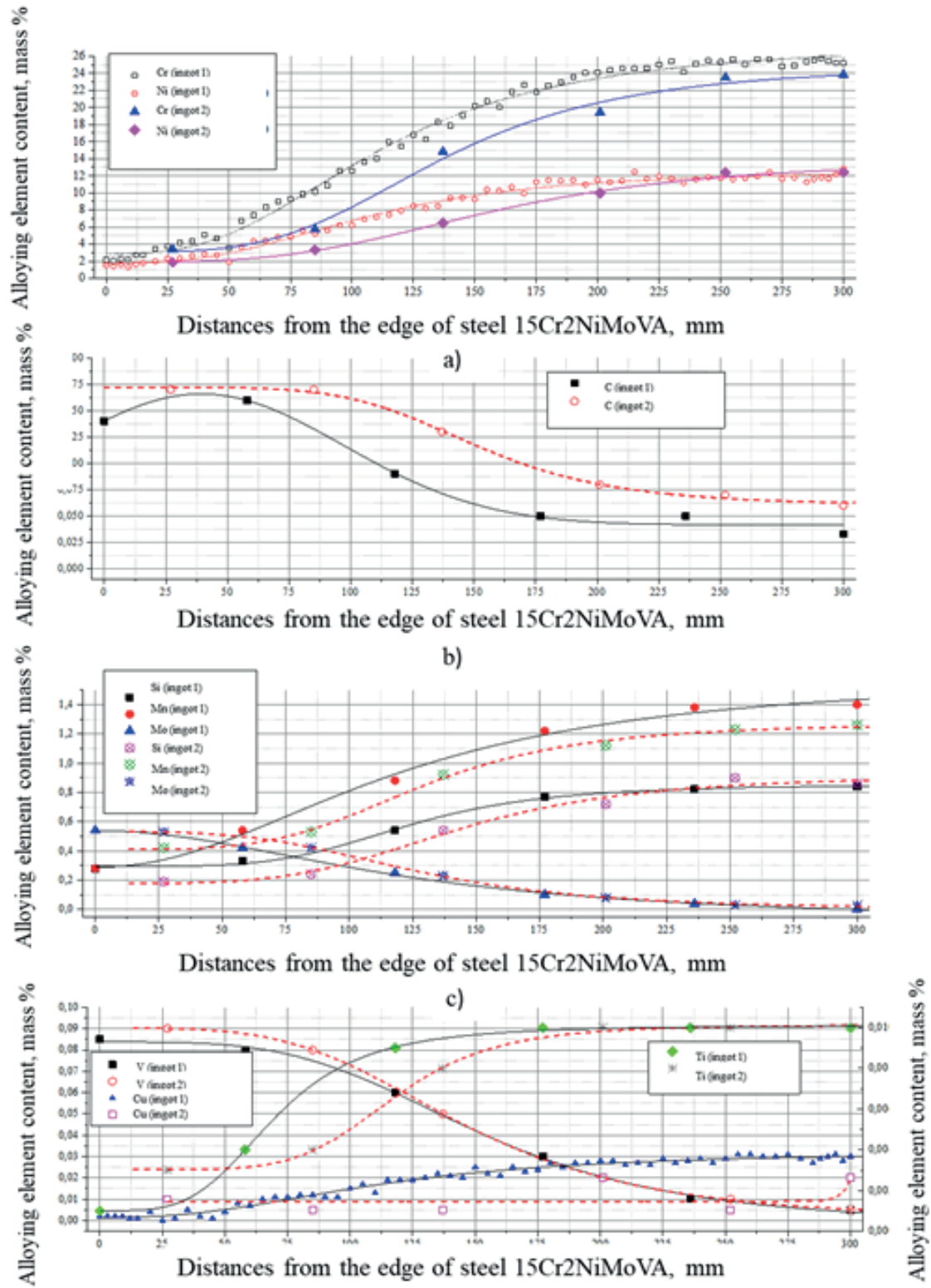

d)

Figure 2: Distribution of alloying elements of ingots 1 and 2 of variable chemical composition. a distribution of chromium and nickel; b - distribution of carbon; c - distribution of silicon, manganese and molybdenum; $d$ - distribution of vanadium, copper and titanium.

region of the austenite-martensitic structure, with an austenite content of more than $70 \%$.

At distances of $6 \mathrm{~mm}, 50 \mathrm{~mm}, 110 \mathrm{~mm}, 170 \mathrm{~mm}$ and $297 \mathrm{~mm}$ from the edge (steel ${ }_{15} \mathrm{Cr} 2 \mathrm{NiMoVA}$ ), microstructural analysis of ingot 1 is performed (Figure 6). The structure of the ingot at a distance of $6 \mathrm{~mm}$ from the edge is a typical structure of steel ${ }_{15} \mathrm{Cr} 2 \mathrm{NiMoVA}$ bainite tempering and ferrite (Figure 6a). An increase in the chromium content leads to the formation of martensite with carbide hardening (Figure 6b). An 


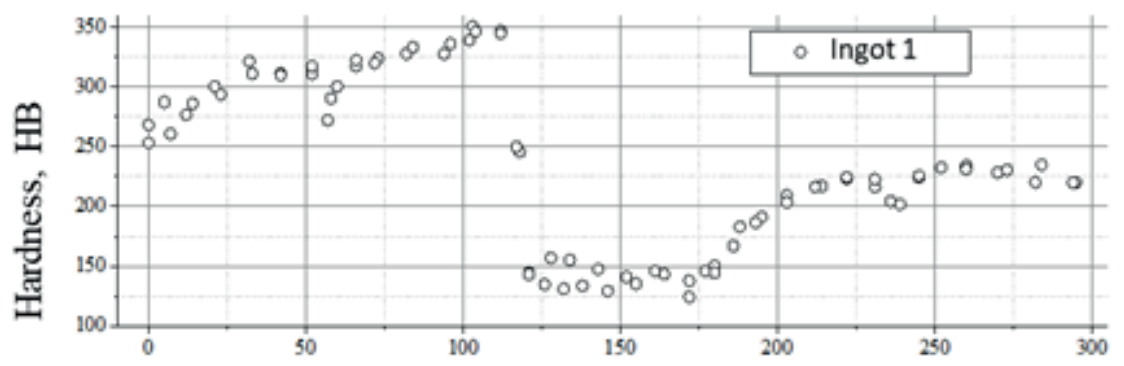

Distances from the edge of steel $15 \mathrm{Cr} 2 \mathrm{NiMoVA}, \mathrm{mm}$ (ingot 1)

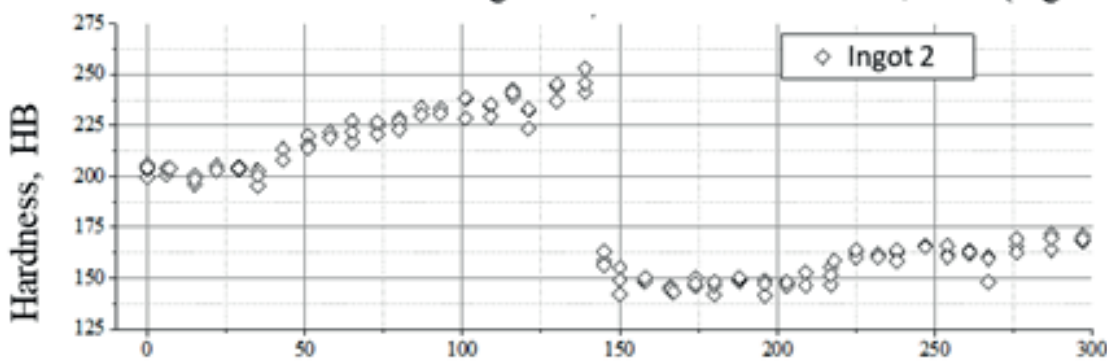

Distances from the edge of steel $15 \mathrm{Cr} 2 \mathrm{NiMoVA}, \mathrm{mm}$ (ingot 2)

Figure 3: The change in hardness over the section of an ingot of an alloy of variable chemical composition (along the axis).
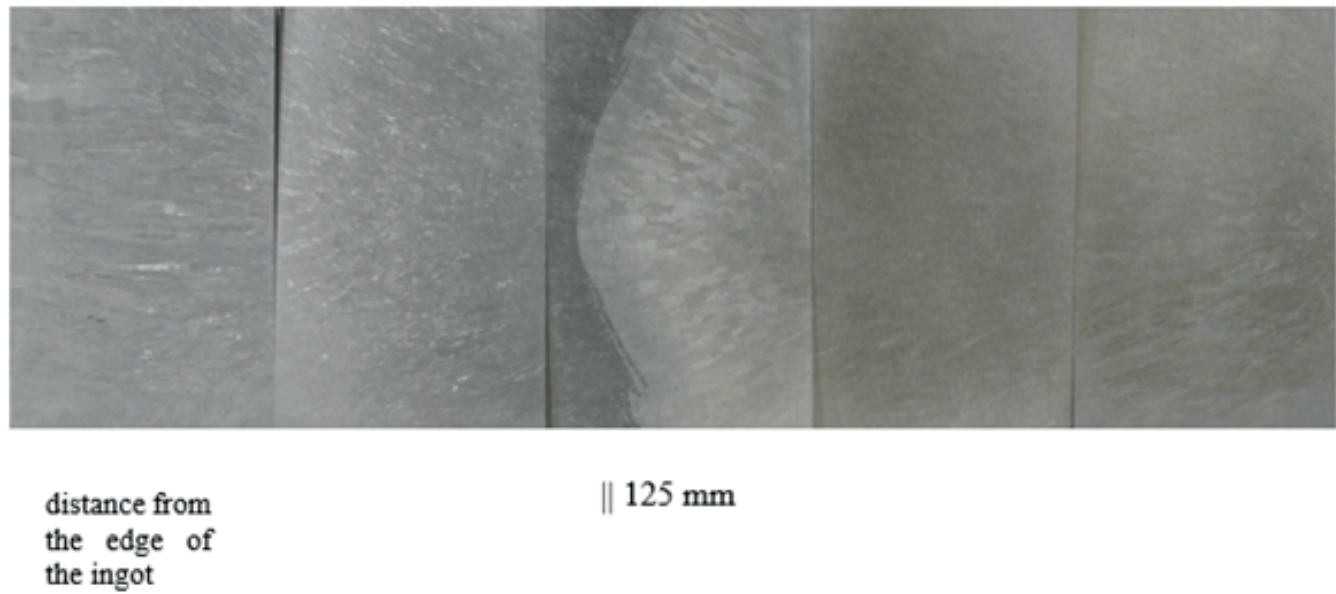

Figure 4: Macrostructure of the ingot of variable chemical composition (ingot 1).

increase in the nickel content converts the ingot into the region of a two-phase structure (a mixture of the martensitic and austenite structure). The structures of martensite and austenite are characterized by different etchability. Thus, the structure of martensite, ferrite with carbide hardening, in the strongly weathered region is revealed (Figure 6c), austenite with martensite at the grain boundaries and carbides is detected in the weakly-weaving region (Figure $6 \mathrm{~d}$ ). The microstructure of the ingot at a distance of $170 \mathrm{~mm}$ from the edge is an austenitic matrix with delta-ferrite precipitates located in the interdendritic regions (Figure $6 \mathrm{e}$ ). The high content of chromium in the solid 


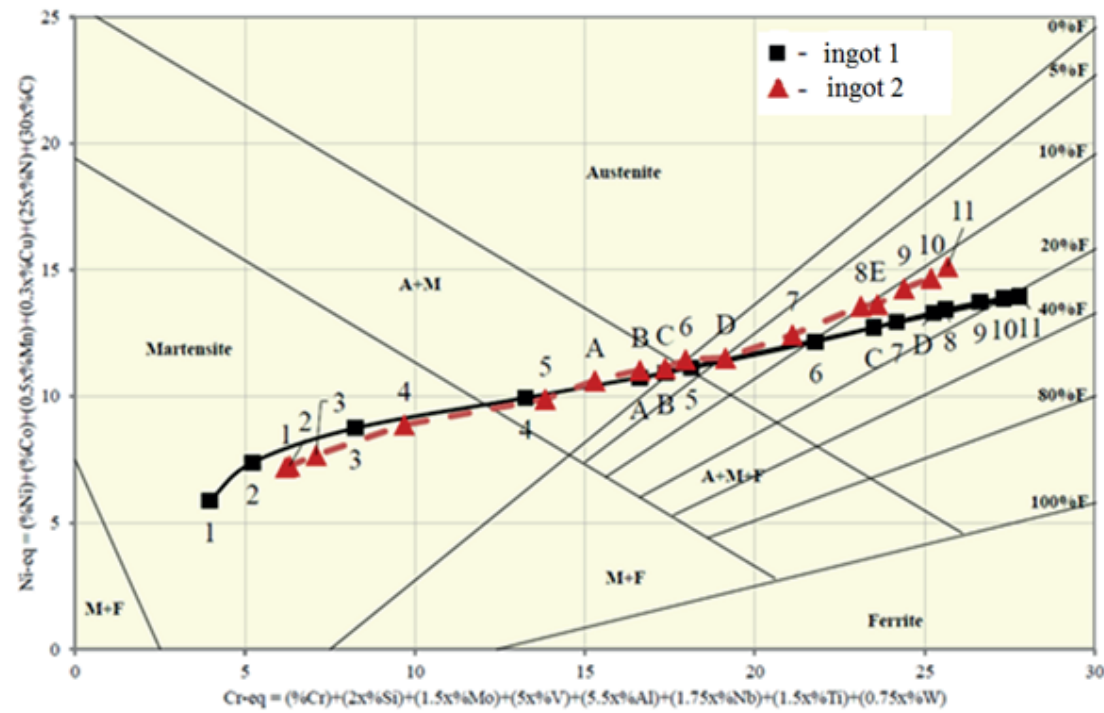

Figure 5: Analysis of the structural state of ingots 1 and 2 of variable chemical composition along the ingot axis.

solution leads to the separation of the intermetallic sigma phase from the austenite matrix (Figure 6f).

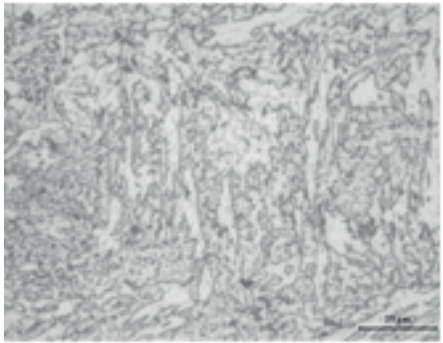

a)

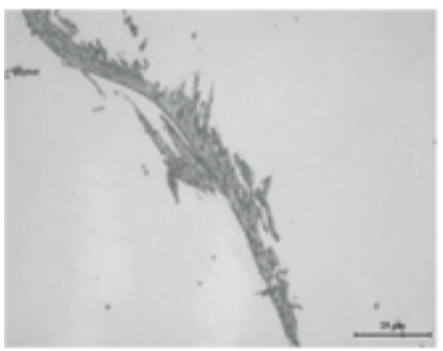

r)

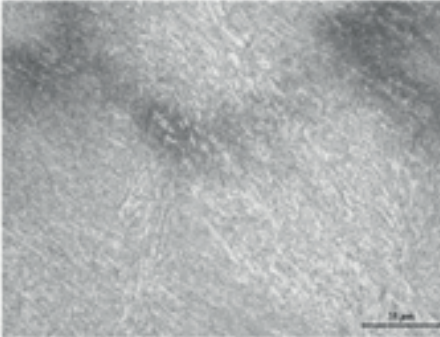

6)

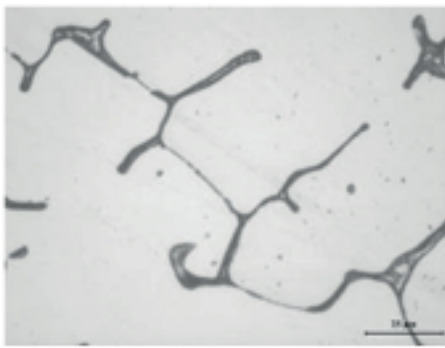

д)

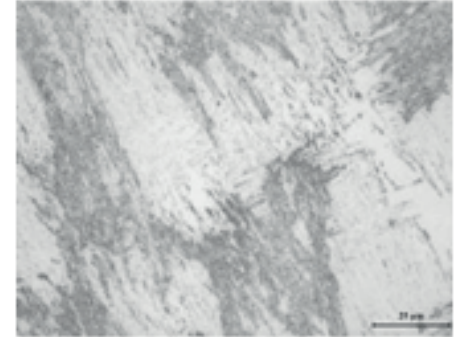

B)

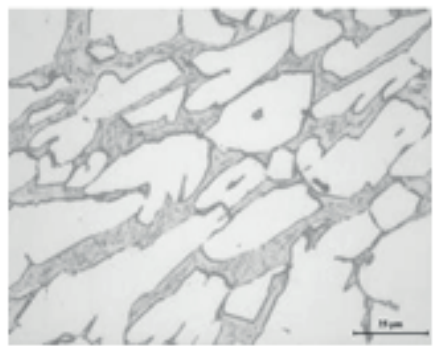

e)

Figure 6: Investigation of the microstructure of the ingot 1 of a variable chemical composition along the ingot axis. a $-6 \mathrm{~mm}$ from the edge; $b-50 \mathrm{~mm}$ from the edge; $\mathrm{c}-110 \mathrm{~mm}$ from the edge (area of strong etching); $d-110 \mathrm{~mm}$ from the edge (area of weak etching); $\mathrm{e}-170 \mathrm{~mm}$ from the edge; $f-297 \mathrm{~mm}$ from the edge. 


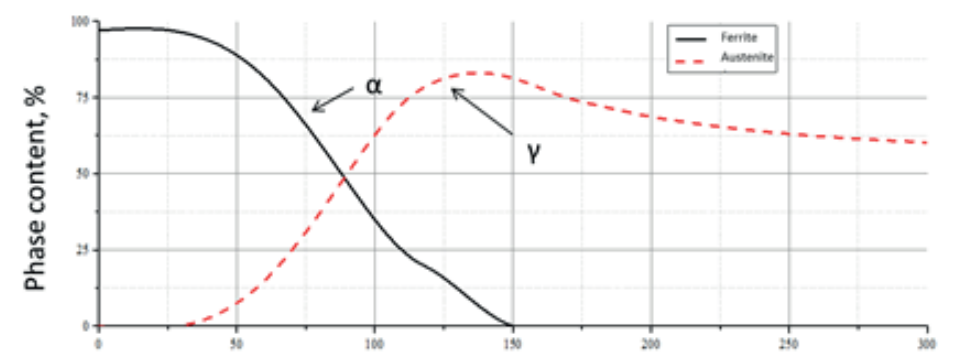

Distance from the edge of steel $15 \mathrm{Cr} 2 \mathrm{NiMoVA}, \mathrm{mm}$ (ingot 1)

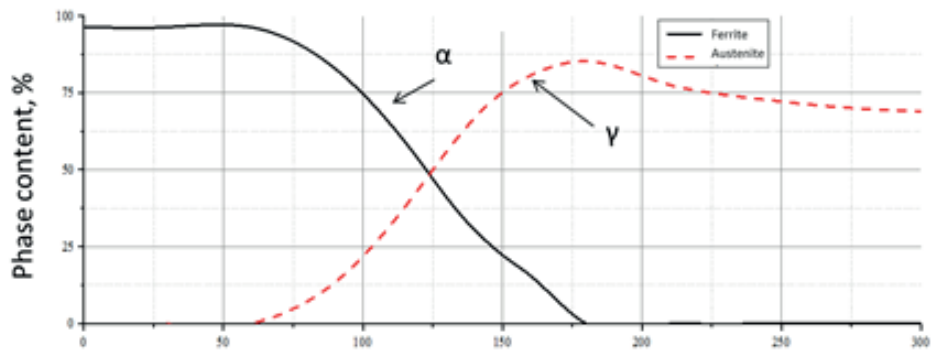

Distance from the edge of steel $15 \mathrm{Cr} 2 \mathrm{NiMoVA}$, mm (ingot 2)

Figure 7: Equilibrium content of the ferrite and austenite phase in an alloy of variable chemical composition at a temperature of $650^{\circ} \mathrm{C}$ along the axis of the ingot calculated in the Thermo-Calc.

A comparison of the results of a direct study of the microstructure with the results obtained using the Scheffler diagram shows a greater degree of accuracy of the data obtained by calculation.

\subsection{Phase composition}

The calculation of the phase composition of the ingots was carried out using thermodynamic modeling methods using the program Thermo-Calc (database for TCFE 6.0 steels). The calculation of the phase composition of the ingots was carried out using thermodynamic modeling methods using the program Thermo-Calc (database for TCFE 6.0 steels). Data on the chemical composition for 11 uniformly distributed sections along the length of the ingot (o mm, $30 \mathrm{~mm}$, etc.) were used. Also, several crosssections were chosen at the places of sharp changes in the values of hardness. Data on the chemical composition of the cross sections were obtained by interpolation of the results of the studies on the distribution of alloying elements (paragraph 3.1). The calculation was carried out at atmospheric pressure and the temperature of the final heat treatment (tempering at $\mathrm{T}=650^{\circ} \mathrm{C}$ ).

With the help of thermodynamic calculations, it was found that at a temperature of $650^{\circ} \mathrm{C}$ for an ingot of variable chemical composition, the ferrite, austenite, sigma phase, $\mathrm{M}_{23} \mathrm{C} 6$ carbide, and titanium carbides ( $\mathrm{TiC}$ ) and vanadium (VC) phases are stable. The 
volume fraction of titanium carbide (TiC) and vanadium (VC) is less than $1 \%$. The distribution of ferrite and austenite along the axis is shown in Figure 7.

The distribution of the basic austenitic and ferrite phases for both ingots is identical. The austenitic phase begins to form at a distance of 30-40 mm (ingot 1) and 50-60 mm (ingot 2) from the edge, which corresponds to the grade composition of ${ }_{15} \mathrm{C} r 2 \mathrm{NiMoVA}$ steel, with nickel content for the first ingot and second ingot about 2-3 mass $\%$ and the carbon content in the first ingot is $0.155-0.165 \mathrm{wt} \%$ and ingot 2 is about $0.175 \mathrm{wt} \%$. The structure becomes completely austenitic with a nickel content of 9-9.5 wt \% and chromium of $19.5-20.5 \mathrm{wt} \%$ for both ingots.

The study showed that an increase in the chromium content above $16.5-17.5 \%$ by weight percent results in a thermodynamically stable intermetallic sigma phase. The content of the phase in ingots can reach up to $29-31 \%$ of the volume fraction of the phases, with a chromium concentration of $24 \%$ by weight (ingot 1 ) and $26 \%$ by weight (ingot 2). In the equilibrium state, in the ingot, carbides of the $\mathrm{M}_{23} \mathrm{C} 6$ type, whose content reaches up to $4 \%$ of the volume fraction and carbides VC, ( Ti, V) C and TiC, whose content was much less than $1 \%$ of the volume fraction of the phases, are observed in the ingot.

\section{Discussion}

The study shows that the ingots simulating the fusion zone of welded joints and cladding have a high degree of heterogeneity: a large gradient in the distribution of chemical elements, a large fracture of hardness values, and a high scatter of hardness values over the cross section. Repeated electroslag remelting is one of the ways to reduce the degree of heterogeneity, equalize the concentration of alloying elements and reduce the spread of hardness values.

Using phase and structural analysis, it was shown that the increase in the hardness values of ingots in the first section is due to solid-solution hardening of the matrix by chromium and nickel and an increase in the content of the $\mathrm{M}_{23} \mathrm{C} 6$ carbide phase. The drop in hardness is most likely due to the transition to the austenitic structure. The secondary increase in hardness is associated with the release of a strong sigma phase.

Table 2 shows the volume fractions of the ferrite and austenite phase in the region of large hardness heterogeneity obtained using Thermo-Calc. It is shown that when the content of the volume fraction of austenite exceeds $71 \%-77 \%$, the hardness value drops sharply. A close result is shown by the results obtained using calculations from 
the Scheffler diagram, the discontinuity of the hardness values is observed when the amount of austenite phase is increased by more than $70 \%$ of the volume fraction of the phases.

TABLE 2: Volume fraction of ferrite and austenite in ingots of variable chemical composition near the zone of sharp changes in hardness.

\begin{tabular}{|c|c|c|c|c|}
\hline Ingot & $\begin{array}{c}\text { Distances from } \\
\text { the edge of steel } \\
\text { 15Cr2NiMoVA, } \\
\text { mm }\end{array}$ & $\begin{array}{c}\text { Volume fraction } \\
\text { of ferrite, } \%\end{array}$ & $\begin{array}{c}\text { Volume fraction } \\
\text { of austenite, } \%\end{array}$ & $\begin{array}{c}\text { The ratio of the } \\
\text { amount of ferrite } \\
\text { to austenite }\end{array}$ \\
\hline Ingot 1 & 110 & 24,8 & 73,1 & $24,8 / 73,1$ \\
\hline 115 & 21,3 & 76,7 & $21,3 / 76,7$ \\
\hline Ingot 2 & 120 & 18,7 & 79,4 & $18,7 / 79,4$ \\
\hline 140 & 30,4 & 66,8 & $30,4 / 66,8$ \\
\hline 145 & 26,1 & 71,4 & $26,1 / 71,4$ \\
\hline
\end{tabular}

\section{Conclusion}

1. It is found that the zone of alloying steels of two different classes of steels has a non-uniform change in the basic properties: distribution of alloying elements, changes in hardness, structure and phase composition.

2. It is shown that the ingots have a region of sharp change in hardness, in which a large gradient in the distribution of chemical elements and phase composition and a sharp change in hardness are observed. Probably, the area of sharp change in hardness can be considered the most vulnerable area in the destruction. The use of repeated electroslag remelting to ingot 2 resulted in a noticeable decrease in the gradient of the inhomogeneity of the properties.

3. Thermodynamic and structural analysis showed that the region of sharp difference in the values of hardness is achieved at a ratio of the volume fraction of austenitic to ferritic phase $(71-76) \%$ to $(29-24) \%$ for both ingots. 


\section{Acknowledgments}

The work was supported by the Ministry of Education and Science of the Russian Federation in the framework of the Grant Agreement No. 14.579.21.0116 (the unique identifier of the agreement RFMEFI57915X0116).

\section{References}

[1] Hanninen $\mathrm{H}$. et al. Dissimilar metal weld joints and their performance in nuclear power plant and oil refinery conditions //VTT TIEDOTTEITA. - 2006. - T. 2347.

[2] Mokhov V.A., Zubchenko A.S., Akbashev I.F., Semishkin V.P. The reactor vessel of the VVER-TOI project. Construction and construction materials // Scientific and technical collection "Problems of Atomic Science and Technology". Series "Ensuring the safety of nuclear power plants": OKB "GIDROPRESS", issue. 34. Materials and technology of manufacturing of equipment RU 2014. - 128 p.

[3] Szávai S., Bezi Z., Ohms C. Numerical simulation of dissimilar metal welding and its verification for determination of residual stresses //Frattura ed Integritá Strutturale. - 2016. - №. 36. - C. 36.

[4] Chaudhari R., Parekh R., Ingle A. Reliability of dissimilar metal joints using fusion welding: A Review //International Conference on Machine Learning, Electrical and Mechanical Engineering (ICMLEME: 2014). - 2014.

[5] Alber Sadek Dissimilar materials weldability concepts// Technology Lead - Materials Engineering EWI// December 15, 2015

[6] Shahid F., Khan A. A., Hameed M. S. Mechanical And Microstuctural Analysis of Dissimilar Metal Welds //International Journal of Research and Reviews in Applied Sciences. - 2015. - T. 25. - №. 1. - C. 6.

[7] Rajamaki P., Karkhin V. A., Homich P. N. Analysis of chemical inhomogeneity near fusion weld interface." //International conference on total welding management in industrial applications", 3rd Join conference, Lappeenranta. - 2007. - C. 263-277.

[8] Maksimets N.A., Negoda E.N. Technology of welding of special steels // Proc. allowance. - Vladivostok: Publishing house FESTU.-2007.-149s.

[9] Saghafifar H. Microstructural stability of a nickel-based alloy overlay on a 2.25 Сr1Mo steel substrate : дис. - University of Nottingham, 2011.

[10] Lukas H. L. et al. Computational thermodynamics: the Calphad method. - Cambridge : Cambridge university press, 2007. - T. 131. 
[11] Saunders N. et al. The application of CALPHAD calculations to Ni-based superalloys //ROLLS ROYCE PLC-REPORT-PNR. - 2000. - C. all-all.

[12] Olson D. L. Prediction of austenitic weld metal microstructure and properties //Welding journal. - 1985. - T. 64. - №. 10. - C. 2815-295S.

[13] Aleshin N. P. et al. Microstructure and composition of welds of Fe 3 Al intermetallic with austenitic corrosion-resistant steels //Metal Science and Heat Treatment. 2011. - T. 52. - №. 9. - C. 437-441. 